Article

\title{
Aromatic Plants: Antioxidant Capacity and Polyphenol Characterisation
}

\author{
Charalampos Proestos ${ }^{1, *}$ and Theo Varzakas ${ }^{2}$ \\ 1 Laboratory of Food Chemistry, Department of Chemistry, National and Kapodistrian University of Athens, \\ Athens 15771, Greece \\ 2 Technological Educational Institute (TEI) Peloponnese, Department of Food Technology, \\ Antikalamos, Kalamata 24100, Greece; theovarzakas@yahoo.gr \\ * Correspondence: harpro@chem.uoa.gr; Tel.: +30-210-727-4160
}

Academic Editor: Barry J. Parsons

Received: 1 March 2017; Accepted: 2 April 2017; Published: 4 April 2017

\begin{abstract}
The antioxidant properties and polyphenol content of some selected aromatic plants grown in Greece were studied. Plants were refluxed with $60 \%$ methanol after acid hydrolysis. The phenolic substances were quantified by High Performance Liquid Chromatography-Diode Array Detector (HPLC-DAD). The antioxidant capacity of the extracts was determined with the Rancimat test using sunflower oil as substrate. Free radical scavenging activity was measured using the stable free radical 1,1-diphenyl-2-picrylhydrazyl (DPPH). Results were compared with standard butylated hydroxytoluene (BHT) and ascorbic acid. Total phenol concentration of the extracts was estimated with Folin-Ciocalteu reagent using gallic acid as standard. All plant extracts examined showed antioxidant capacity and contained phenolic compounds. Caffeic acid was detected in all the examined plant extracts. Ferulic acid was also detected in all the methanolic extracts, except from $P$. lanata, in rather high concentration. The amount of total phenolics varied slightly in plant materials and ranged from $8.2 \mathrm{mg}$ to $31.6 \mathrm{mg}$ of gallic acid/g dry sample. The highest amount was found in O. dictamnus, and the lowest in N. melissifolia.
\end{abstract}

Keywords: aromatic plants; HPLC; antioxidant capacity; DPPH; Rancimat test

\section{Introduction}

Aromatic plants are considered as perfect sources of natural antioxidants [1], such as phenolic substances, usually referred as polyphenols, which are ubiquitous components of plants and herbs. Polyphenols are antioxidants with redox properties which allow them to act as reducing agents, hydrogen donators, and singlet oxygen quenchers. Some show metal chelation properties $[2,3]$ and in addition some have antimicrobial activity [4]. A great number of aromatic plants have been reported as having anti-inflammatory, antiallergic, antimutagenic, antiviral antithrombotic, and vasodilatory actions [5].

For example, dictamnus is an aromatic plant found in Crete and it was used from ancient times against stomach pains and as an effective painkiller and wound healing agent. Eucalyptus is one of the most known aromatic plants in the world trade market. It grows in Australia and in Mediterranean countries. Oregano is very often used in Greek cuisine as seasoning due to its strong flavour. It contains glycosides such as apigenin, luteonin, diosmetin [6]. Green tea, such as sideritis, as well as black tea, has been examined by many researchers for their content in polyphenols. In plant materials it is difficult to determine individual flavonoid glycosides. Therefore, the glycosides are hydrolysed and the resulting aglycones are identified and quantified [7].

High performance liquid chromatography (HPLC) is a chromatographic technique which is very common for the simultaneous separation and quantification of phenolic substances. In this 
study, the identification of each compound was based on a combination of retention time and spectral matching.

The objective of this study was the determination of phenolic compounds in selected plant extracts as well as the evaluation of the antioxidant capacity of the examined extracts in different test systems.

\section{Materials and Methods}

\subsection{Plant Materials and Reagents}

The part of the plants examined and the drying method used are presented in Table 1. Dried samples were obtained commercially or collected from different sites in Greece. All samples were analysed within 3 months of collection. Gallic acid, gentisic acid, p-coumaric acid, vanillic acid, ferulic acid, syringic acid, (+)-catechin, quercetin, apigenin, naringenin, myricetin, were purchased from Sigma-Aldrich (Steinheim, Germany). Luteolin was from Roth (Karlsruhe, Germany). Caffeic acid was from Merck (Darmstadt, Germany). (-)-Epicatechin was from Fluka AG (Buchs, Switzerland). Rutin was from Alexis Biochemicals (Lausen, Switzerland). Ascorbic acid, p-hydroxybenzoic acid and BHT (butylated hydroxytoluene) were a kind donation from the National Agricultural Research Foundation (N.AG.RE.F, Greece). Quantification was done via a calibration with standards (external standard method). All standards were prepared as stock solutions in methanol. Working standards were made by diluting stock solutions in $62.5 \%$ aqueous methanol containing BHT $1 \mathrm{~g} / \mathrm{L}$, and $6 \mathrm{~mol} / \mathrm{L} \mathrm{HCl}$ to yield concentrations ranging between $0.5 \mathrm{mg} / \mathrm{L}-25 \mathrm{mg} / \mathrm{L}$. Stock/working solutions of the standards were stored in darkness at $-18^{\circ} \mathrm{C}$. All solvents and reagents from various suppliers were of the highest purity needed for each application. The Folin-Ciocalteu reagent was purchased from Merck (Darmstadt, Germany). 1,1-diphenyl-2-picrylhydrazyl (DPPH) was obtained from Sigma-Aldrich (Steinheim, Germany).

Table 1. Total Phenolics in Plant Extracts and their Antioxidant Capacity (Expressed as PF Values).

\begin{tabular}{|c|c|c|c|c|c|c|}
\hline Family Species & Collection Sites & Part Examined & Drying Method $^{\text {a }}$ & $\begin{array}{c}\text { Total Phenolics b } \\
\text { (mg Gallic Acid/g ds) }\end{array}$ & $\mathrm{PF}^{\mathrm{c}}$ (Ground Material) & PF (Methanol Extracts) \\
\hline Origanum dictamnus & Crete & Leaves & Air & $8.2 \pm 0.3$ & 1.3 & 1.2 \\
\hline Eucalyptus globules & Attiki & Leaves & Air & $10.5 \pm 0.3$ & 1.5 & 1.4 \\
\hline Origanum vulgare & Euboea & Leaves & $\mathrm{F} / \mathrm{v}$ & $18.4 \pm 0.3$ & 1.8 & 1.7 \\
\hline Phlomis cretica & Crete & Leaves & $\mathrm{F} / \mathrm{v}$ & $16.2 \pm 0.1$ & 2.1 & 1.9 \\
\hline Phlomis lanata & Crete & Leaves & $\mathrm{F} / \mathrm{v}$ & $21.4 \pm 0.3$ & 2.4 & 2.1 \\
\hline Nepeta melissifolia & Crete & Leaves & $\mathrm{F} / \mathrm{v}$ & $31.6 \pm 0.4$ & 3.1 & 2.9 \\
\hline
\end{tabular}

\subsection{Extraction Procedure}

The extraction method used for dried samples has as follows: $40 \mathrm{~mL}$ of $60 \%$ aqueous methanol containing BHT $(1 \mathrm{~g} / \mathrm{L})$ was added to $0.5 \mathrm{~g}$ of dried sample. Then $10 \mathrm{~mL}$ of $6 \mathrm{~mol} / \mathrm{L} \mathrm{HCl}$ were added. The mixture was stirred carefully. In each sample nitrogen was bubbled for ca. 40-60 s. The extraction mixture was then sonicated for $15 \mathrm{~min}$ and refluxed in a water bath at $90{ }^{\circ} \mathrm{C}$ for $2 \mathrm{~h}$. The mixture was then filtered and made up to $100 \mathrm{~mL}$ with methanol furthermore filtered quickly through a $0.45 \mu \mathrm{m}$ membrane filter (Millex-HV, Millipore Corporation, Billerica, MA, USA) and injected to HPLC.

\subsection{Determination of Total Phenolics}

Total phenolic content was measured by the Folin-Ciocalteu assay [8]. Quantification was performed with the hydrolysed samples. Results were expressed as mg of gallic acid/g dry sample.

\subsection{HPLC Analysis}

The analytical HPLC system employed consisted of a JASCO high performance liquid chromatograph coupled with a UV-vis multiwavelength detector (MD-910 JASCO, Tokyo, Japan). 
The analytical data were evaluated using a JASCO data processing system (DP-L910/V, Mary's Court, Easton, MD 21601 USA). The separation was achieved on a Waters Spherisorb ${ }^{\circledR} 5 \mu \mathrm{m}$ ODS2 $4.6 \times 250 \mathrm{~mm}$ column at ambient temperature. The mobile phase consisted of water with $1 \%$ glacial acetic acid (solvent $A$ ), water with $6 \%$ glacial acetic acid (solvent $B$ ), and water-acetonitrile $(65: 30, v / v)$ with 5\% glacial acetic acid (solvent C). The gradient used was: 100\% A 0-10 $\mathrm{min}, 100 \%$ B 10-30 min, $90 \%$ B $/ 10 \%$ C $30-50 \mathrm{~min}, 80 \%$ B / 20\% C $50 \mathrm{~min}-60 \mathrm{~min}, 70 \% \mathrm{~B} / 30 \%$ C $60-70 \mathrm{~min}, 100 \%$ C $70-105 \mathrm{~min}$, 100\% A 105-110 min; post time 10 min before next injection [9]. The flow rate was $0.5 \mathrm{~mL} / \mathrm{min}$ and the injection volume was $20 \mu \mathrm{L}$. The monitoring wavelength was $280 \mathrm{~nm}$ for the phenolic acids and 320 and $370 \mathrm{~nm}$ (flavones, flavonoles). The identification of each compound was based on a combination of retention time and spectral matching. Linear regression analysis using the least squares method was used to evaluate the calibration curve of each analyte as a function of its concentration. To calculate the reproducibility of the analyses, each phenolic compound was analysed at different concentrations. Results of the HPLC analysis are expressed as the mean of three extractions and triplicate assays. Means, the standard deviation (SDs) and the coefficient of variation $(\% \mathrm{CV})$ were calculated. The imprecision was less than $4.0 \%$, apart from luteolin (6.9\%). Analytical characteristics of the method are presented in Table 2.

Table 2. Analytical characteristics of method for the high performance liquid chromatography (HPLC) analysis.

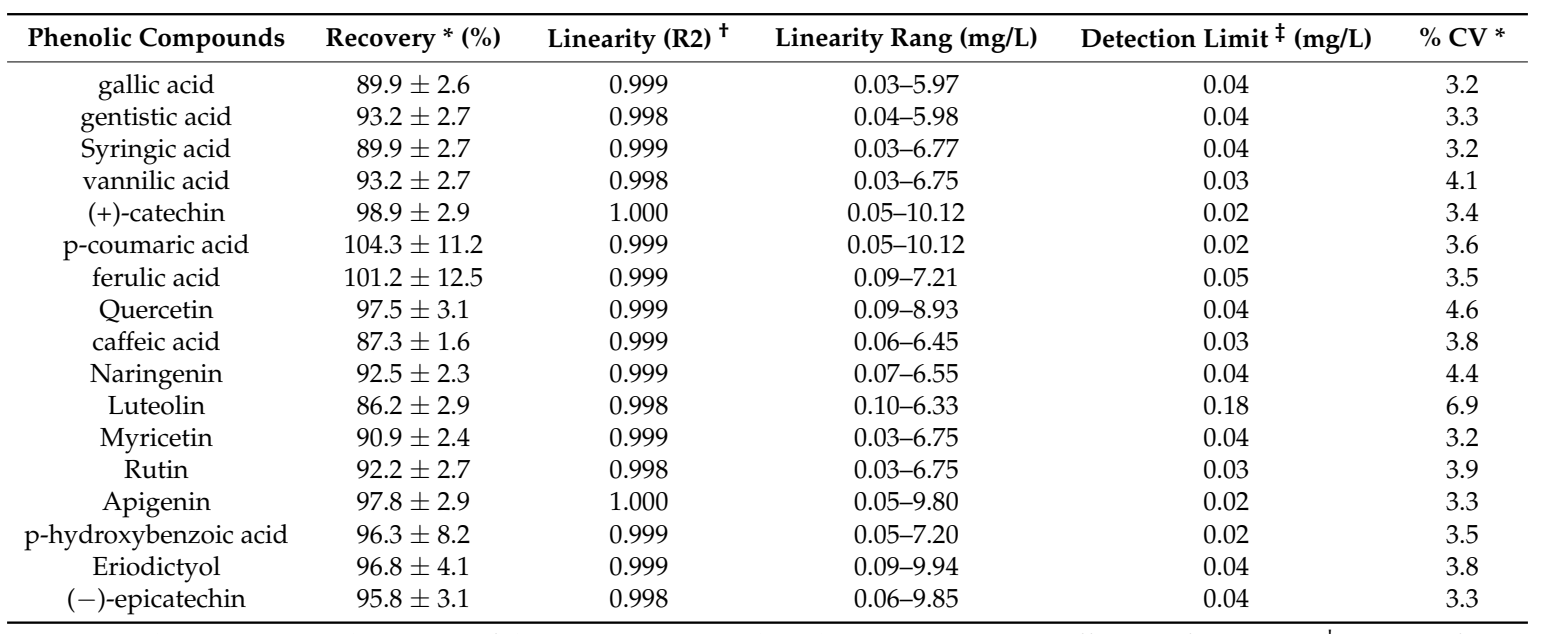

${ }^{*}$ Results are expressed as mean of three extractions and triplicate assays; $\mathrm{CV}$, coefficient of variation; ${ }^{+}$Square of regression coefficient; $\ddagger^{\ddagger}$ Three times the noise level.

\subsection{1, 1-Diphenyl-2-Picrylhydrazyl (DPPH) Scavenging Activity}

Experiments were carried out according to the method of Blois [10] with a slight modification. Briefly, a $1 \mathrm{mmol} / \mathrm{L}$ solution of DPPH radical solution in methanol was prepared and then, $1 \mathrm{~mL}$ of this solution was mixed with $3 \mathrm{~mL}$ of sample solutions in different concentrations. After $30 \mathrm{~min}$, the absorbance was measured at $517 \mathrm{~nm}$. The \% DPPH radical scavenging is calculated in the equation:

$\% \mathrm{DPPH}$ radical-scavenging $=\left(\left(\mathrm{Abs}_{\mathrm{control}}-\mathrm{Abs}_{\text {sample }}\right) / \mathrm{Abs}_{\text {control }}\right) \times 100$.

The DPPH solution without sample solution was used as control. $\mathrm{IC}_{50}$ values of extracts were calculated by using the calibration \% DPPH radical-scavenging $=\mathrm{f}($ concentration $(\mu \mathrm{g} / \mathrm{mL}))$ for each plant and expressed in $\mu \mathrm{g} / \mathrm{mL}$. 


\subsection{Rancimat Test}

Samples of sunflower oil (3.5 g) containing $0.02 \%$ extract or $2 \%$ ground material were subjected to oxidation at $110{ }^{\circ} \mathrm{C}$ (air flow $20 \mathrm{~L} / \mathrm{h}$ ). Induction periods, IP (h), were recorded automatically. The protection factors (PF) were calculated according to the following formula [11]:

$$
\left(\mathrm{PF}=\mathrm{IP}_{\text {extract }} / \mathrm{IP}_{\text {control }}\right)
$$

\section{Results and Discussion}

The present method is simple, easy to use, and effective enough for the identification and quantification of major phenolic compounds in aromatic plants. This has been reported by other authors, who have used the same method of extraction and analysis of major Flavonoid aglycones $[1,7,12]$. Generally, reversed phase HPLC with $C_{18}$ columns is the most popular technique for the analysis of polyphenols in different foods, despite the fact that the separation of procyanidins is not satisfactory with these phases [13]. Spherisorb $C_{18}$ stationary phase, which was used in this study to separate phenolic acids and flavonoids in aromatic plants, produce quite good results. After extraction and acid hydrolysis the content of phenolic substances were determined. Quantification was done via a calibration with standards (external standard method). The amount of phenolic acids detected in the analysed samples is shown in Table 3. Additionally, the content of flavonoids identified in the same plant extracts is shown in Table 4. Results are expressed in mg/100 g dry sample. (+)-Catechin, quercetin and rutin were the most abundant flavonoids. Quercetin has been reported to be present in a large number of aromatic plants [1]. Rutin (quercetin 3-o-rhamnose glycoside) was present along with 22 other flavones, flavonoles and their glycosides in tea leaves [14]. Rutin in some cases can be hydrolysed to quercetin (aglycone). Caffeic acid was detected in all the examined plant extracts. Ferulic acid was also detected in all the methanolic extracts, except from P. lanata, in rather high concentration. Phenolic acids are found in nature as esters and rarely as glycosides or in free form [15]. General comments have been published [16-18]. Thus, hydrolysis was needed for the identification and quantitative determination of phenolic acids. The data presented in Tables 2 and 3 are considered as indicative of phenolic content of these aromatic plants. Papers about most of the examined plant extracts are very scarce in the literature. Among others, time of harvest, storage conditions, are considered responsible for the observed variations in the phenolic content.

The antioxidant capacity (expressed as PF values) and the total phenolic content of all extracts are shown in Table 1 . The amount of total phenolics varied slightly in plant materials and ranged from $8.2 \mathrm{mg}$ to $31.6 \mathrm{mg}$ of gallic acid/g dry sample. The highest amount was found in O. dictamnus, and the lowest in N. melissifolia. Similar amounts in plant phenolics from herbs and medicinal plants collected in Finland have been reported recently [8].

The outcome of the Rancimat test supports the hypothesis that aromatic plants are good sources of natural antioxidants such as phenolic compounds. When working accurately, this method offers an efficient, simple and automated assay. When ground material was added to sunflower oil, protection factors were slightly higher compared to the addition of methanol extracts. Similar PF values for ethanol and acetone extracts of plants of Greek origin have been reported [11]. 
Table 3. Content of phenolic acids in the examined plant extracts (expressed in mg/100 g dry sample ${ }^{\mathrm{a}}$ ).

\begin{tabular}{|c|c|c|c|c|c|c|c|c|}
\hline Plant & Gallic Acid & Gentisic Acid & Caffeic Acid & $p$-Coumaric Acid & Vanillic Acid & Syringic Acid & Ferulic Acid & $p$-Hydroxybenzoic Acid \\
\hline Origanum dictamnus (A) & $4.9 \pm 0.03$ & ND & $13.5 \pm 0.02$ & $13.9 \pm 0.04$ & $18.5 \pm 0.02$ & ND & $16.9 \pm 0.04$ & ND \\
\hline Eucalyptus globules (B) & ND & ND & $8.1 \pm 0.01$ & $6.6 \pm 0.02$ & ND & ND & $12.3 \pm 0.03$ & ND \\
\hline Sideritis cretica $(\mathrm{C})$ & $1.1 \pm 0.02$ & ND & $3.3 \pm 0.02$ & ND & ND & ND & $6.8 \pm 0.02$ & $2.5 \pm 0.01$ \\
\hline Origanum vulgare (D) & ND & ND & $6.4 \pm 0.02$ & ND & ND & ND & $10.4 \pm 0.03$ & ND \\
\hline Phlomis cretica (E) & ND & ND & $2.2 \pm 0.01$ & ND & ND & ND & $5.1 \pm 0.02$ & ND \\
\hline Phlomis lanata (F) & $14 \pm 0.02$ & $3.2 \pm 0.03$ & $20 \pm 0.03$ & $4.1 \pm 0.02$ & $2 \pm 0.02$ & $1.1 \pm 0.02$ & ND & $1.5 \pm 0.01$ \\
\hline Nepeta melissifolia (G) & $20 \pm 0.02$ & $4.3 \pm 0.03$ & $26 \pm 0.03$ & $5.2 \pm 0.02$ & $2.7 \pm 0.02$ & $2.6 \pm 0.02$ & $22.4 \pm 0.03$ & $5.4 \pm 0.01$ \\
\hline Mentha pulegium $(\mathrm{H})$ & ND & ND & $13.5 \pm 0.02$ & ND & $13.5 \pm 0.02$ & ND & $13.5 \pm 0.02$ & ND \\
\hline
\end{tabular}

${ }^{a}$ Results are expressed as mean $(\mathrm{mg} / 100 \mathrm{~g}$ dry sample \pm standard deviation) of three extractions and triplicate assays; ND = not detected.

Table 4. Flavonoid content in the examined plant extracts (expressed in $\mathrm{mg} / 100 \mathrm{~g}$ dry sample ${ }^{\mathrm{a}}$ ).

\begin{tabular}{ccccccccc}
\hline Plant & Quercetin & Apigenin & Luteolin & Naringenin & Myricetin & Rutin & (+)-Catechin Hydrated & (-)-Epicatechin \\
\hline Origanum dictamnus & $52 \pm 0.09$ & ND & ND & ND & ND & ND & $1.9 \pm 0.01$ & ND \\
Eucalyptus globules & ND & ND & ND & ND & ND & $10 \pm 0.03$ & ND & ND \\
Sideritis cretica & ND & ND & ND & ND & ND & ND & $6.9 \pm 0.02$ & $2.8 \pm 0.01$ \\
Origanum vulgare & $7.3 \pm 0.02$ & ND & ND & ND & ND & $2.3 \pm 0.01$ & $2.5 \pm 0.01$ & ND \\
Phlomis cretica & $1.2 \pm 0.01$ & ND & ND & ND & ND & ND & $1.5 \pm 0.01$ \\
Phlomis lanata & $2.2 \pm 0.01$ & ND & ND & ND & ND & $4.5 \pm 0.01$ & ND & $2.6 \pm 0.01$ \\
Nepeta melissifolia & $11.2 \pm 0.02$ & $5.6 \pm 0.02$ & ND & ND & $1.8 \pm 0.01$ & $2.4 \pm 0.01$ & $5.5 \pm 0.02$ \\
Mentha pulegium & ND & $6.9 \pm 0.02$ & ND & $4.7 \pm 0.02$ & ND & ND & $3.5 \pm 0.01$ & ND \\
\hline
\end{tabular}

${ }^{a}$ Results are expressed as mean $(\mathrm{mg} / 100 \mathrm{~g}$ dry sample \pm standard deviation) of three extractions and triplicate assays; $\mathrm{ND}=$ not detected. 
The DPPH method was evidently introduced nearly 50 years ago by Madsen Blois [10], and it is widely used to test the ability of compounds to act as free radical scavengers or hydrogen donors, and to evaluate antioxidant capacity. The parameter $\mathrm{EC}_{50}$ ("efficient concentration" value) otherwise called the $\mathrm{IC}_{50}$ value, is used for the interpretation of the results from the DPPH method and is defined as the concentration of substrate that causes $50 \%$ loss of the DPPH activity (colour). The $\mathrm{EC}_{50}$ parameter has the drawback that the higher the antioxidant capacity, the lower is the value of $\mathrm{EC}_{50}$. This is a disadvantage particularly when results are presented graphically as a bar chart even if the same data are also available in numerical form. $\mathrm{IC}_{50}$ values of Nepeta melissifolia, Mentha pulegium and Phlomis lanata $(5.1 \pm 0.4,13.5 \pm 0.5,23.9 \pm 0.4 \mu \mathrm{g} / \mathrm{mL})$ were found to be similar to BHT and ascorbic acid $(18.5 \pm 0.4,3.9 \pm 0.3 \mu \mathrm{g} / \mathrm{mL})$. All the $\mathrm{IC}_{50}$ values of the examined plant extracts are presented in Figure 1.

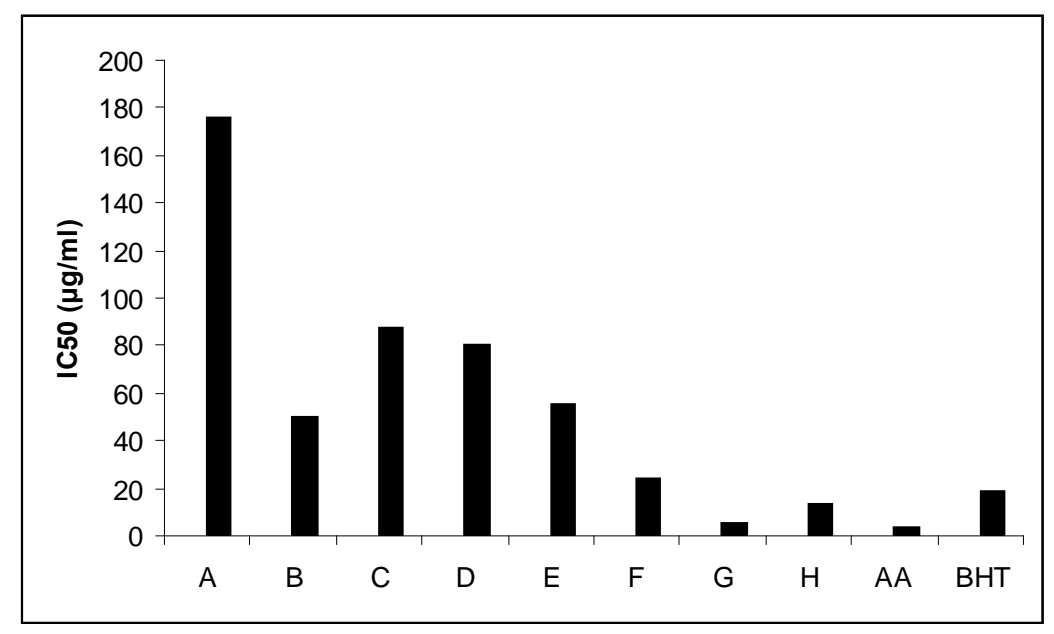

Figure 1. Free radical scavenging activities, where: AA stands for Ascorbic acid; (A) Origanum dictamnus; (B) Eucalyptus globules; (C) Sideritis cretica; (D) Origanum vulgare; (E) Phlomis cretica; (F) Phlomis lanata; (G) Nepeta melissifolia; (H) Mentha pulegium. BHT, butylated hydroxytoluene.

\section{Conclusions}

The results in this study indicate that the examined aromatic plants contain certain amounts of polyphenols and their antioxidant capacity was shown. The extracts showed adequate DPPH scavenging activity. Their efficiency toward oxidation of bulk oil under accelerated conditions also produced satisfactory results using the Rancimat apparatus.

Acknowledgments: The authors would like to thank National and Kapodistrian University of Athens special accounts for funding the project.

Author Contributions: Each author contributed equally to this research article.

Conflicts of Interest: The authors declare no conflict of interest.

\section{References}

1. Justesen, U.; Knuthsen, P. Composition of flavonoids in fresh herbs and calculation of flavonoid intake by use of herbs in traditional Danish dishes. Food Chem. 2001, 73, 245-250. [CrossRef]

2. Kähkönen, M.P.; Hopia, A.I.; Heikki, J.V.; Rauha, J.P.; Pihlaja, K.; Kujala, T.S.; Heinonen, M. Antioxidant activity of plant extracts containing phenolic compounds. J. Agric. Food Chem. 1999, 47, 3954-3962. [CrossRef] [PubMed]

3. Rice-Evans, C.A.; Packer, L. Flavonoids in herbs. In Flavonoids in Health and Disease; Marcel Dekker Inc.: New York, NY, USA, 1998; Volume 2, pp. 43-70. 
4. $\quad$ Rauha, J.P.; Remes, S.; Heinonen, M.; Hopia, A.; Kähkönen, M.; Kujala, T.; Pihlaja, K.; Vuolera, H.; Vuolera, P. Antimicrobial effects of Finnish plant extracts containing flavonoids and other phenolic compounds. Int. J. Food Microbiol. 2000, 56, 3-12. [CrossRef]

5. Hollman, P.C.H.; Hertog, M.G.L.; Katan, M.B. Analysis and health effects of flavonoids. Food Chem. 1996, 57, 43-46. [CrossRef]

6. Justesen, U. Negative atmospheric pressure chemical ionisation low-energy collision activation mass spectrometry for the characterisation of flavonoids in extracts of fresh herbs. J. Chrom. A 2000, 902, 369-379. [CrossRef]

7. Nuutila, A.M.; Kammiovirta, K.; Oksman-Caldentey, K.M. Comparison of methods for the hydrolysis of flavonoids and phenolic acids from onion and spinach for HPLC analysis. Food Chem. 2002, 76, 519-525. [CrossRef]

8. Kähkönen, M.P.; Hopia, A.I.; Heikki, J.V.; Rauha, J.-P.; Pihlaja, K.; Kujala, T.S.; Heinonen, M. Antioxidant activity of plant extracts containing phenolic compounds. J. Agric. Food Chem. 1999, 47, 3954-3962. [CrossRef] [PubMed]

9. Suarez, B.; Picinelli, A.; Mangas, J.J. Solid-phase extraction and high-performance liquid chromatographic determination of polyphenols in apple musts and ciders. J. Chrom. A 1996, 727, 203-209. [CrossRef]

10. Blois, M.S. Antioxidant determinations by the use of a stable free radical. Nature 1958, 181, 1199-1200. [CrossRef]

11. Exarchou, V.; Nenadis, N.; Tsimidou, M.; Gerothanasis, I.P.; Troganis, A.; Boskou, D. Antioxidant activities and phenolic composition of extracts from Greek oregano, Greek sage, and summer savory. J. Agric. Food Chem. 2002, 50, 5294-5299. [CrossRef] [PubMed]

12. Mattila, P.; Astola, J.; Kumpulainen, J. Determination of flavonoids in plant material by HPLC with diode-array and electro-array detections. J. Agric. Food Chem. 2000, 48, 5834-5841. [CrossRef] [PubMed]

13. Justesen, U.; Knuthsen, P.; Torben, T.J. Quantitative analysis of flavonols, flavones, and flavanones in fruits, vegetables and beverages by high-performance liquid chromatography with photo-diode array and mass spectrometric detection. J. Chrom. A 1998, 799, 101-110. [CrossRef]

14. Finger, A.; Kuhr, S.; Engelhardt, H.U. Chromatography of tea constituents. J. Chrom. 1992, 624, $293-315$. [CrossRef]

15. Lee, S.H.; Widmer, W.B. Phenolic compounds. In Handbook of Food Analysis; Marcel Dekker Inc.: New York, NY, USA, 1996; Volume 1, pp. 821-894.

16. Proestos, C.; Boziaris, I.S.; Nychas, G.-J.E.; Komaitis, M. Analysis of flavonoids and phenolic acids in Greek aromatic plants: Investigation of their antioxidant capacity and antimicrobial activity. Food Chem. 2006, 95, 664-671. [CrossRef]

17. Proestos, C.; Chorianopoulos, N.; Nychas, G.-J.E.; Komaitis, M. RP-HPLC analysis of the phenolic compounds of plant extracts. Investigation of their antioxidant capacity and antimicrobial activity. J. Agric. Food Chem. 2005, 53, 1190-1195. [CrossRef] [PubMed]

18. Proestos, C.; Sereli, D.; Komaitis, M. Determination of phenolic compounds in aromatic plants by RP-HPLC and GC-MS. Food Chem. 2006, 95, 44-52. [CrossRef]

(C) 2017 by the authors. Licensee MDPI, Basel, Switzerland. This article is an open access article distributed under the terms and conditions of the Creative Commons Attribution (CC BY) license (http:/ / creativecommons.org/licenses/by/4.0/). 